\title{
Hyperthyroidism Evokes Myocardial Ceramide Accumulation
}

\author{
Agnieszka Mikłosz Bartłomiej Łukaszuk Adrian Chabowski Filip Rogowski \\ Krzysztof Kurek Małgorzata Żendzian-Piotrowska
}

Department of Physiology, Medical University of Białystok, Białystok, Poland

\section{Key Words}

Ceramide • Triiodothyronine $\cdot$ Sphingolipids $\cdot$ Heart - Mitochondrial proteins $\cdot$ Fatty acids oxidation

\begin{abstract}
Background: Thyroid hormones (THs) are key regulators of cardiac physiology as well as modulators of different cellular signals including the sphingomyelin/ceramide pathway. The objective of this study was to examine the effect of hyperthyroidism on the metabolism of sphingolipids in the muscle heart. Methods: Male Wistar rats were treated for 10 days with triiodothyronine $\left(T_{3}\right)$ at a dose of $50 \mu \mathrm{g} / 100 \mathrm{~g}$ of body weight. Animals were then anaesthetized and samples of the left ventricle were excised. Results: We have demonstrated that prolonged, in vivo, $\mathrm{T}_{3}$ treatment increased the content of sphinganine (SFA), sphingosine (SFO), ceramide (CER) and sphingomyelin (SM), but decreased the level of sphingosine-1-phosphate (S1P) in cardiac muscle. Accordingly, the changes in sphingolipids content were accompanied by a lesser activity of neutral sphingomyelinase and without significant changes in ceramidases activity. Hyperthyroidism also induced activation of AMP-activated protein kinase (AMPK) with subsequently increased expression of mitochondrial proteins: cytochrome c oxidase IV (COX IV), $\beta$-hydroxyacyl-CoA dehydrogenase ( $\beta$-HAD), carnityne palmitoyltransferase I (CPT I) and nuclear peroxisome proliferator-activated receptor- $\gamma$ coactivator- $1 \alpha(\mathrm{PGC} 1 \alpha)$. Conclusions: We conclude that prolonged $\mathrm{T}_{3}$ treatment increases sphingolipids metabolism which is reflected by higher concentration of SFA and CER in heart muscle. Furthermore, hyperthyroidisminduced increase in heart sphingomyelin (SM) concentration might be one of the mechanisms underlying maintenance of CER at relatively low level by its conversion to SM together with decreased S1P content.
\end{abstract}




\section{Introduction}

Thyroid hormones (THs) are key regulators of cardiac physiology. Firstly, directly by enhancing fatty acids (FAs) and glucose utilization as a compensation for increased myocardial workload [increased heart rate (HR) or systolic pressure]. Secondly, several genes encoding important structural and regulatory proteins in the myocardium, including myosin isoform expression, calcium cycling proteins and protein kinases, are thyroid hormone responsive $[1,2]$. These direct effects of $\mathrm{T}_{3}$ cellular actions are mediated by its nuclear and membrane receptors ( $\alpha$ and/or $\beta$ THR receptors). It seems that in heart triiodothreonine effects result from the binding of $\mathrm{T}_{3}$ to nuclear thyroid hormone receptors, which belong to the superfamily of steroid hormone receptors [3]. These effects are, at least partially, controlled by the peroxisome proliferator-activated receptors (PPAR $\alpha, \beta / \delta$ and $\gamma$ ) and their co-activators (i.e. peroxisome proliferator-activated receptor- $\gamma$ coactivator- $1 \alpha$ - PGC- $1 \alpha /$ PPARGC1A) or corepressors (i.e. nuclear receptor interacting protein 1 - NRIP1/RIP140) [4, 5]. In opposite, the non-genomic effects result in activation of different intracellular signaling pathways involving Akt/protein B (PKB) and AMP activated protein kinase (AMPK) that activate the transport of ions (calcium, sodium and potassium) across the plasma membrane, glucose transport, and mitochondrial gene expression [6, 7]. Activation of AMPK and Akt/PKB protein can be considered as rapid metabolic response, leading to increased fatty acid oxidation and glycolysis via enzyme phosphorylation and gene transcription initiation [8,9]. It was previously shown that $\mathrm{T}_{3}$ can induce activation of specific kinases leading to phosphorylation of AMPK in skeletal muscle tissue $[8,10]$ as well as PKB, which has been shown to be activated through phosphorylation by $\mathrm{T}_{3}$ in rat cardiomyocyes [11]. So far, there is no evidence that $\mathrm{T}_{3}$ may interact or influence the behavior of myocardial sphingolipids. This class of lipids belong to a group of lipid-derived molecules, containing a sphingoid base as a backbone to which is attached a single fatty acid (FA) side-chain of varying length and degree of saturation [12, 13]. Among sphingolipids, most of the interest has been placed to the biological function of ceramide, because of its involvement in lipotoxicity, apoptosis, proliferation, differentiation, growth arrest, inflammation and pathogenesis of insulin resistance [14-17]. The amount of ceramide is determined by a balance between the rate of its formation and degradation. Ceramide is generated through de novo synthesis, salvage pathway (by ceramidases), and sphingomyelin cycle (by sphingomyelinases) (Fig. 1) [14,15, 18]. The first and rate-limiting step of de novo process is catalyzed by the enzyme serine palmitoyltransferase (SPT), to form 3-ketosphinganine $[12,13,19,20]$. The final two steps of this pathway involve the generation of dihydroceramide from sphinganine (SFA), by the action of dihydroceramide synthase, and its subsequent conversation into ceramide by dihydroceramide desaturase $[13,21]$. In addition, the ceramide can be further modified into alternative forms, including glucosylceramide and ceramide 1-phosphate [13]. In contrast, degradation of ceramide occurs mainly by its deacylation and formation of sphingosine in a reaction catalyzed by specific ceramidases: acid (aCDase), neutral (nCDase) and alkaline (alCDase). However, it is well known that acid ceramidase activity in the rat heart is definitely lower than the activity of alkaline or neutral ceramidase isoforms of this enzyme. Therefore, this isoform probably does not play significant role in the generation of myocardial ceramide pool [22]. Finally, sphingosine can be phosphorylated by sphingosine kinase to form sphingosine-1-phosphate (S1P). There are also differences for the expression of sphingosine kinase isoforms. It is noteworthy that SphK1 is dominant subtype in the human myocardium, whereas the rodent heart expresses predominantly SphK2 [22]. Besides de novo synthesis, ceramide can also be produced by the action of sphingomyelinases (SMases) (Fig. 1). Therefore, ceramide level may be regulated by distinct mechanisms and in distinct compartments. In support of the notion are the data indicating that hypothyreosis results in a reduction in the content of CER in the skeletal muscles, liver and heart [23]. On other hand, CER has been proposed to be a mediator of cardiomyocyte apoptosis induced by ischemia-reperfusion. It was shown that hypoxia-reoxygenation rapidly activates neutral sphingomyelinase in rat cardiomyocytes which results in the accumulation of CER [24]. 


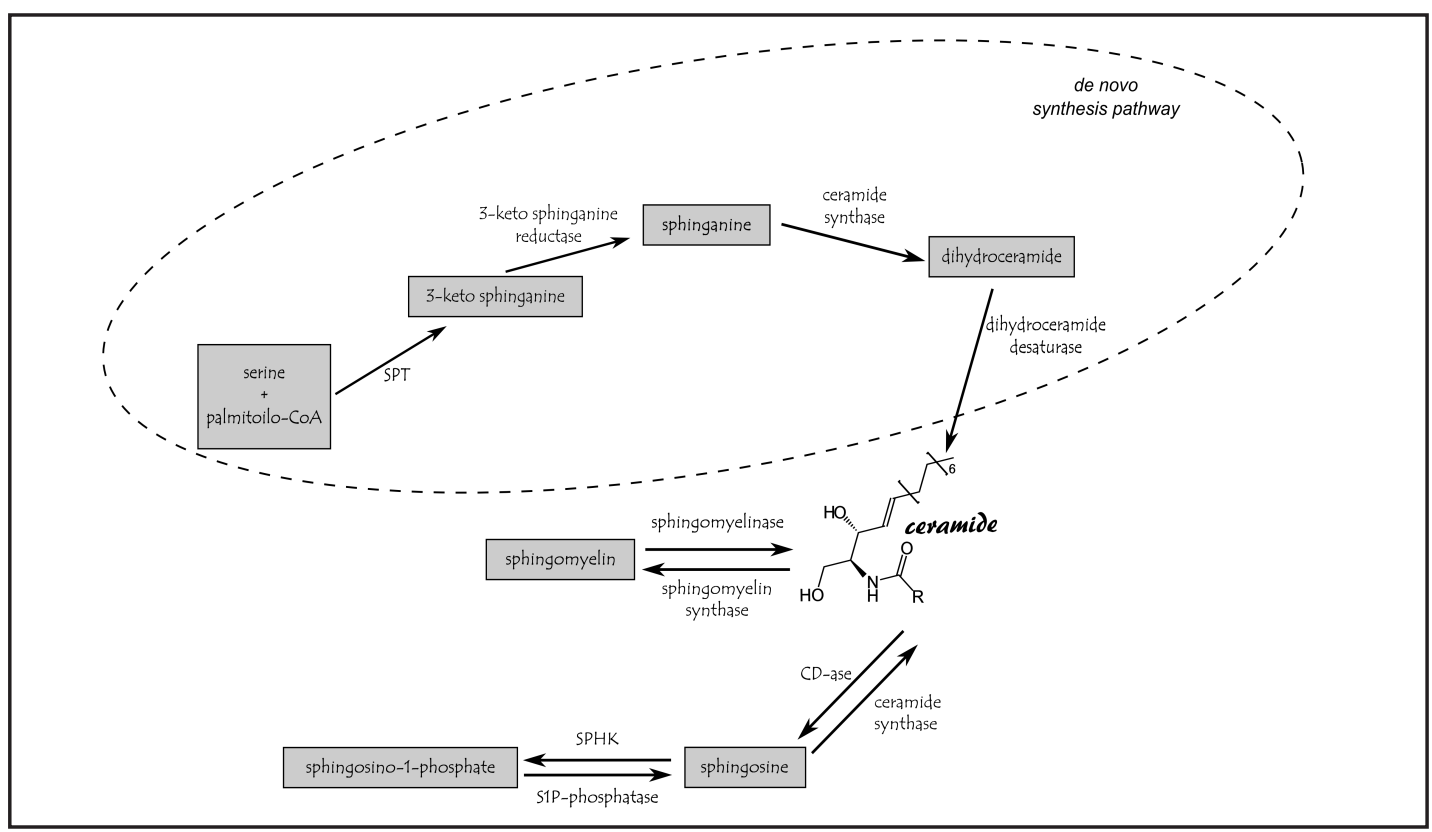

Fig. 1. Schematic representation of metabolism of free sphingoid bases and their 1-phosphates. SPT - serine palmitoyltransferase, CD-ase - ceramidase, SPHK - sphingosine kinase, S1P-phosphatase - sphingosine-1phosphate phosphatase.

However, so far there are no data available on the effect of hyperthyroidism on the metabolism of sphingolipids in the heart. Therefore, hyperthyroidism was induced in rats in vivo and consequently the activity of key enzymes of ceramide metabolism (neutral sphingomyelinase, acid sphingomyelinase, neutral ceramidase, alkaline ceramidase) as well as the content of sphingolipid metabolism products (sphinganine, ceramide, sphingosine, sphingosine-1-phosphate and sphingomyelin) was measured.

\section{Materials and Methods}

\section{Animals and study design}

All animal experiments were conducted in accordance with the guidelines of the Ethical Committee for Animal Experiments at the Medical University of Bialystok. Adult male Wistar rats (250-280 g) were housed under controlled conditions $\left(21^{\circ} \mathrm{C} \pm 2,12 \mathrm{~h}\right.$ light/12 h dark cycle) with unrestricted access to water and standard laboratory rat chow. The animals were randomly divided into two groups: control $(\mathrm{n}=8)$ and treated with triiodothyronine $\left(\mathrm{T}_{3}\right)(\mathrm{n}=8)$. Triiodothyronine (Sigma Aldrich, St. Louis, MO) was injected subcutaneously at a dose of $50 \mathrm{\mu g} / 100 \mathrm{~g}$ of body weight, daily for 10 days, as reported elsewhere [25]. This dose is commonly used to mimic hyperthyroidism in humans [26]. Control animals were treated with $0,9 \%$ saline. The animals were in a fasted state at the time of sacrifice and tissue collection. $24 \mathrm{~h}$ after the last $\mathrm{T}_{3}$ injection, the rats were anesthetized by intraperitoneal injection of pentobarbital with a dose of $80 \mathrm{mg} / \mathrm{kg}$ of body weight.

Samples of the left ventricle were excised, cleaned of the blood and immediately freeze-clamped with aluminum tongs precooled in liquid nitrogen. Blood taken from the abdominal aorta was collected to sodium-heparinized tubes, centrifuged, then the plasma was separated and flash-frozen in liquid nitrogen. All samples were stored at $-80^{\circ} \mathrm{C}$ until further analysis.

\section{Plasma triiodothyronine (T3) and glucose concentration}

$\mathrm{T}_{3}$ concentration was measured in plasma, with commercially available kit, according to the manufacturer's instruction (Rat Triiodothyronine, $\mathrm{T}_{3}$ ELISA kit, EIAab). Glucose was measured by the enzymatic method using a 2300 STAT Plus glucose analyzer (YSI, US). 
Concentration of free fatty acids and sphingomyelin

Plasma levels of free fatty acids (FFAs) and intramuscular sphingomyelin (SM) were analyzed by gas-liquid chromatography (GLC). Studied lipids were extracted using the Folch method of extraction [27] modified according to van der Vusse et al. [28]. Briefly, heart muscle and serum samples were extracted in chloroform-methanol $(2: 1, \mathrm{vol} / \mathrm{vol})$ containing butylated hydroxytoluene $(0.01 \%)$ as an antioxidant and heptadecanoic acid as an internal standard. Then the lipid samples were separated by thin-layer chromatography silica plates (Kieselgel 60, $0.22 \mathrm{~mm}$, Merck, Darmstadt, Germany) with a heptane: isopropyl ether: acetic acid (60:40:3, vol/vol/vol) resolving solution. Lipid bands were visualized by spraying with a $0.2 \%$ solution of $3^{\prime} 7^{\prime}$-dichlorofluorescin in methanol and identified under ultraviolet light using standards on the plates. Then the gel bands corresponding to the sphingomyelin were scraped off the plate, transferred into screw tubes which contained pentadecanoic acid (Sigma-Aldrich, St. Louis, MO) as an internal standard and transmethylated with $\mathrm{BF}_{3} /$ methanol. Also FFAs were transmethylated with $\mathrm{BF}_{3} /$ methanol. The fatty acid methyl esters (FAMEs) were dissolved in hexane and analyzed by GLC. A HewlettPackard 5890 Series II gas chromatograph with Varian CP-SIL capillary column (100 m, internal diameter of $0.25 \mathrm{~mm}$ ) and flame-ionization detector was used. According to the retention times of standards, the individual long-chain fatty acids were quantified. The content of sphingomyelin was estimated as the sum of the particular fatty acid species and expressed in nanomoles per miligram of protein. Serum levels of FFA was expressed in nanomoles per milliliter of the plasma.

\section{Concentration of sphingoid bases}

Concentration of sphingosine, sphinganine, S1P was measured using the method previously described by Min et al. [29]. Briefly, internal standards (10 pmol of C17-sphingosine and 30 pmol of C17-S1P, Avanti Polar Lipids, USA) were added to the samples before sonication. The dried lipid residues were redissolved in ethanol and sphingoid bases were converted to their o-phthalaldehyde derivatives and analyzed using HPLC system (ProStar, Varian, USA) equipped with a fluorescence detector and C18 reversed-phase column (Varian, OmniSpher 5, $4.6 \times 150 \mathrm{~mm}$ ). The isocratic eluent composition of acetonitrile (Merck, Darmstadt, Germany), water $(9: 1, \mathrm{v} / \mathrm{v})$ and flow rate of $1 \mathrm{~mL} / \mathrm{min}$ were used. The column temperature was maintained at $30^{\circ} \mathrm{C}$.

Concentration of ceramide

A small volume $(50 \mu \mathrm{L})$ of the chloroform phase containing lipids extracted as described above was transferred to a fresh tube containing $40 \mathrm{pmol}$ of $\mathrm{N}$-palmitoyl-D-erythro-sphingosine (C17 base) as an internal standard. The samples were evaporated under a nitrogen stream, redissolved in $1,2 \mathrm{~mL}$ of $1 \mathrm{M} \mathrm{KOH}$ in $90 \%$ methanol and heated at $90^{\circ} \mathrm{C}$ for $60 \mathrm{~min}$ to convert ceramide into sphingosine. This digestion procedure does not convert complex sphingolipids, such as sphingomyelin, galactosylceramide or glucosylceramide, into free sphingoid bases [30]. Samples were then partitioned by the addition of chloroform and water. The upper phase was discarded and the lower phase was evaporated under nitrogen. The content of free sphingosine liberated from ceramide was then analyzed using HPLC as described above. The calibration curve was prepared using N-palmitoylsphingosine (Avanti Polar Lipids) as a standard. The chloroform extract used for the analysis of ceramide contains small amounts of free sphingoid bases. Therefore, the concentration of ceramide was corrected for the level of free sphingosine determined in the same sample.

The activity of neutral SMase and acid SMase

The protein level was estimated in homogenate prior to enzymatic analysis with the BSA protein assay kit (Sigma-Aldrich, St. Louis, MO). As a standard, bovine serum albumin (Sigma-Aldrich, St. Louis, MO) was used.

The activity of neutral and acidic isoforms of sphingomyelinase was determined accordingly to Liu et al. [31] with the use of radiolabeled substrate $\left[\mathrm{N}-\right.$ methyl $\left.{ }^{-14} \mathrm{C}\right]$-sphingomyelin (Perkin-Elmer Life Sciences, Waltham, MA). The product of reaction ${ }^{14} \mathrm{C}$-choline phosphate or ${ }^{3} \mathrm{H}$-L-serine was extracted with $\mathrm{CHCl}_{3} /$ methanol $(2: 1, v / v)$, transferred to scintillation vials and counted using a Packard TRI-CARB 1900 TR scintillation counter.

The activity of neutral CDase and alkaline CDase

The activity of neutral and alkaline ceramidases was measured by the method of Nikolova-Karakashian and Merrill [32]. The activity of the enzymes was determined with the use of radiolabeled [N-palmitoylKARGER 
$\left.1-{ }^{14} \mathrm{C}\right]$-sphingosine (Moravek Biochemicals, Brea, CA) as a substrate. Unreacted ceramide and liberated $1{ }^{-14} \mathrm{C}$-palmitate were separated with the basic Dole solution (isopropanol/heptane/1 N NaOH, 40,10,1, $\mathrm{v} / \mathrm{v} / \mathrm{v}$ ). Radioactivity of the $1-{ }^{14} \mathrm{C}$-palmitate was measured by scintillation counting.

\section{Protein extraction and Western Blot}

Routine Western blotting procedures were used to detect protein content as described previously [33]. The samples were homogenized in ice-cold RIPA (radioimmunoprecipitation assay) buffer ( $50 \mathrm{mM}$ Tris- $\mathrm{HCl}$, $150 \mathrm{M} \mathrm{NaCl}, 1 \mathrm{mM}$ EDTA, 1\% NP-40, 0,25\% Na-deoxycholate, $1 \mathrm{mM}$ phenylmethylsulfonyl fluoride, $1 \mu \mathrm{g} / \mathrm{ml}$ aprotinin, $1 \mu \mathrm{g} / \mathrm{ml}$ leupeptin, $1 \mu \mathrm{g} / \mathrm{ml}$ pepstatin, $1 \mathrm{mM}$ sodium orthovanadate, $1 \mathrm{mM}$ sodium fluoride) for 1 min at $4{ }^{\circ}$ C. Protein concentration was determined using BCA protein assay kit with bovine serum albumin as a standard. Samples were boiled at $95^{\circ} \mathrm{C}$ for 10 minutes in sample buffer containing 2-mercaptoethanol. Protein $(60 \mu \mathrm{g})$ was subjected to SDS-PAGE and transferred to PVDF membranes, followed by blocking membranes in TTBS buffer (50 mM Tris- $\mathrm{HCl}, 130 \mathrm{mM} \mathrm{NaCl}$ and 0,05 \% Tween-20) containing 5\% nonfat dry milk for $90 \mathrm{~min}$ at room temperature. The membranes were then incubated overnight at $4^{\circ} \mathrm{C}$ with the corresponding antibodies at a dilution of 1:1000. Primary antibodies were purchased from Cell Signalling Technology [Akt, phospho-Akt (Ser 473), anti-AMPK $\alpha$, anti-pAMPK $\alpha$ (Thr172)], Santa Cruz Biotechnology (COX IV, $\beta$-HAD, CPT I and PGC1 $\alpha$ ) ) and Novus Biologicals ( $\beta$-tubulin). Thereafter the membranes were incubated with anti-rabbit IgG horseradish peroxidase-conjugated secondary antibody (1:3000; Santa Cruz Biotechnology, USA). Immunoreactive protein bands were visualized by using an enhanced chemiluminescence substrate (Thermo Scientific, USA) and quantified by densitometry (Biorad, USA). Equal protein concentrations were loaded in each lane as confirmed by Ponceau staining on the blot membrane. Protein expression was normalized to $\beta$-tubulin. Finally, the control was set to $100 \%$ and the experimental groups were expressed relatively to the control.

\section{Statistical analyses}

All data are presented as means \pm SD. Statistical analysis of the data was made using unpaired Student's t-test. Statistical significance was set at $\mathrm{P}<0.05$.

\section{Results}

\section{General characteristics}

As previously reported by us $[18,33]$ and others $[1,34]$, prolonged thyroid hormone treatment caused only a small decrease in body weight (Table 1, $-16 \%, \mathrm{P}>0.05$ ), but induced heart hypertrophy as indicated by either increased heart weight and/or size (compared to tibia, data not shown). Furthermore, plasma FFA, glucose and $\mathrm{T}_{3}$ content was significantly increased (Table 1, 5-fold, $+22 \%$ and 4,8-fold, $\mathrm{P}<0.05$, respectively) after $\mathrm{T}_{3}$ administration.

\section{The content of heart sphingolipids}

Sustained $\mathrm{T}_{3}$ provision led to a substantial increase $(\sim 1,5$-fold $)$ in sphinganie level, which is an important substrate for de novo ceramide synthesis (Fig.2A, $\mathrm{P}<0.05$ ). As a consequence, significant enhancement in the content of ceramide (Fig.2B, $+28 \%, \mathrm{P}<0.05$ ) accompanied by a significant increase in sphingosine level (Fig. $2 \mathrm{C},+80 \%, \mathrm{P}<0.05$ ) was noticed. Furthermore, we observed pronounced elevation ( $\sim 5$-fold $)$ of sphingomyelin

Table 1. General features and plasma measurements of the experimental animals. The animals were divided into two groups: control and treated with $\mathrm{T}_{3} . \mathrm{T}_{3}$ was injected subcutaneously with a dose of $50 \mu \mathrm{g} / 100 \mathrm{~g}$ of body weight, daily for 10 days, while control animals were treated with 0,9\% saline. Data are shown as mean \pm SD ( $\mathrm{n}=8$ in each group). ${ }^{*} \mathrm{P}<0.05$ statistically significant difference vs. $\mathrm{T}_{3}$ treatment

\begin{tabular}{lcc}
\hline & Control & $\mathrm{T}_{3}$ \\
\hline Body weight $(\mathrm{g})$ & $307.0 \pm 24.26$ & $254.23 \pm 28.16$ \\
Plasma $\mathrm{T}_{3}$ concentration $(\mathrm{pg} / \mathrm{dl})$ & $240.36 \pm 36.42$ & $200.42 \pm 54.89^{*}$ \\
Plasma glucose $(\mathrm{nM})$ & $6.77 \pm 1.22$ & $8.23 \pm 1.11^{*}$ \\
Plasma FFA concentration $(\mathrm{nmol} / \mathrm{ml})$ & $101.9 \pm 28.79$ & $489.2 \pm 75.75^{*}$ \\
\hline
\end{tabular}



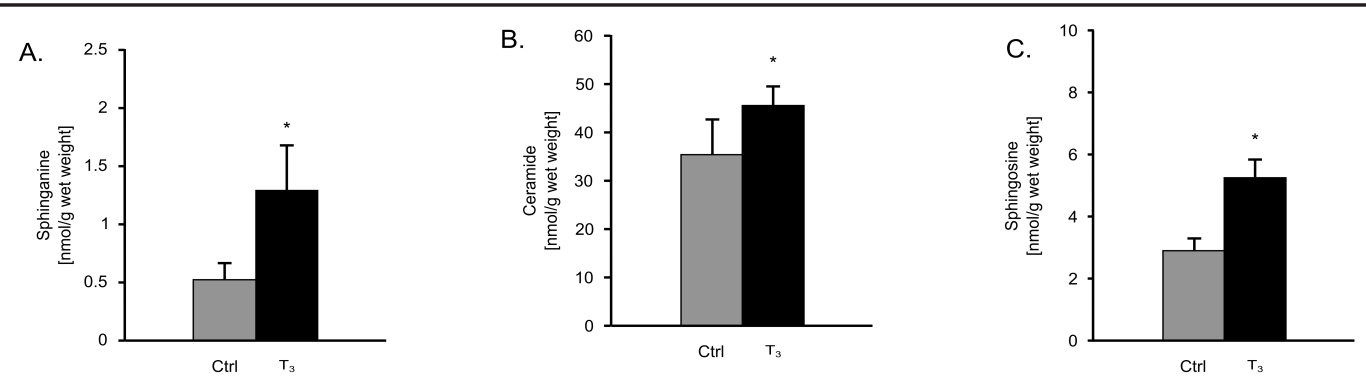

D.
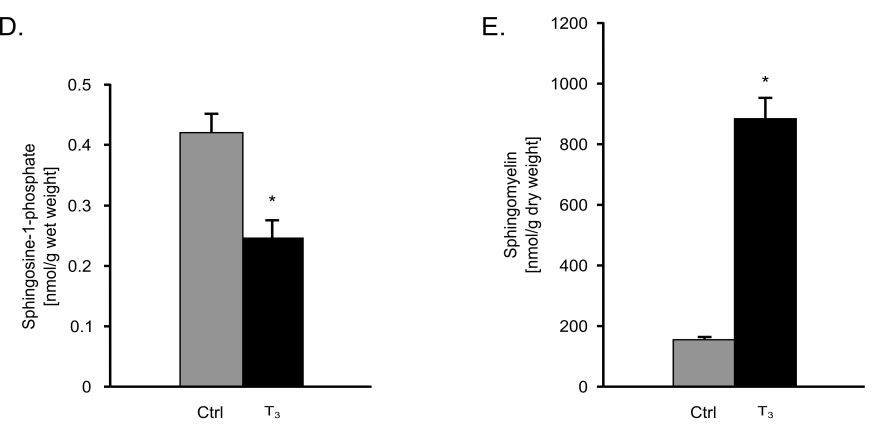

Fig. 2. Effect of hyperthyroidism on the myocardial content of: (A) sphinganine, (B) ceramide, (C) sphingosine, (D) sphingosine-1-phosphate and (E) sphingomyelin. The animals were divided into two groups: control and treated with $\mathrm{T}_{3} . \mathrm{T}_{3}$ was injected subcutaneously with a dose of $50 \mu \mathrm{g} / 100 \mathrm{~g}$ of body weight, daily for 10 days, while control animals were treated with $0,9 \%$ saline. $\mathrm{T}_{3}$ - triodothyronine. Data are shown as mean \pm $\mathrm{SD}$ ( $\mathrm{n}=8$ in each group). ${ }^{*} \mathrm{P}<0.05$ statistically significant difference vs. $\mathrm{T}_{3}$ treatment.
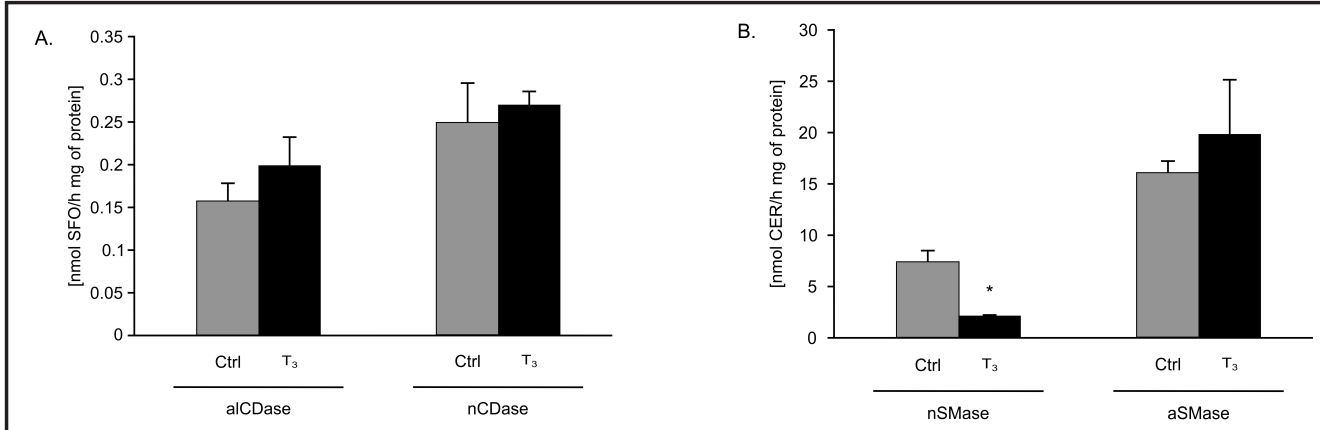

Fig. 3. Effect of hyperthyroidism on the myocardial activity of: (A) alkaline and neutral ceramidases and (B) neutral and acid sphingomyelinases. The animals were divided into two groups: control and treated with $\mathrm{T}_{3}$. $\mathrm{T}_{3}$ was injected subcutaneously with a dose of $50 \mu \mathrm{g} / 100 \mathrm{~g}$ of body weight, daily for 10 days, while control animals were treated with $0,9 \%$ saline. nCDase - neutral ceramidase, alCDase - alkaline ceramidese, nSMase - neutral sphingomyelinase, aSMase - acid sphingomyelinase, $\mathrm{T}_{3}$ - triodothyronine. Data are shown as mean $\pm \mathrm{SD}$ ( $\mathrm{n}=8$ in each group). ${ }^{*} \mathrm{P}<0.05$ statistically significant difference vs. $\mathrm{T}_{3}$ treatment.

content after $\mathrm{T}_{3}$ treatment (Fig.2E, $\mathrm{P}<0.05$ ), that may also contribute to the increase in ceramide content. In contrast, the content of sphingosine-1-phosphate was significantly lower after $\mathrm{T}_{3}$ treatment (Fig.2D, $-42 \%, \mathrm{P}<0.05$ ).

The activities of key enzymes implicated in sphingolipids metabolism

In the next step we checked which enzymes and proteins, involved in regulation of cardiac sphingolipid metabolism, were substantially changed by hyperthyroidism and 


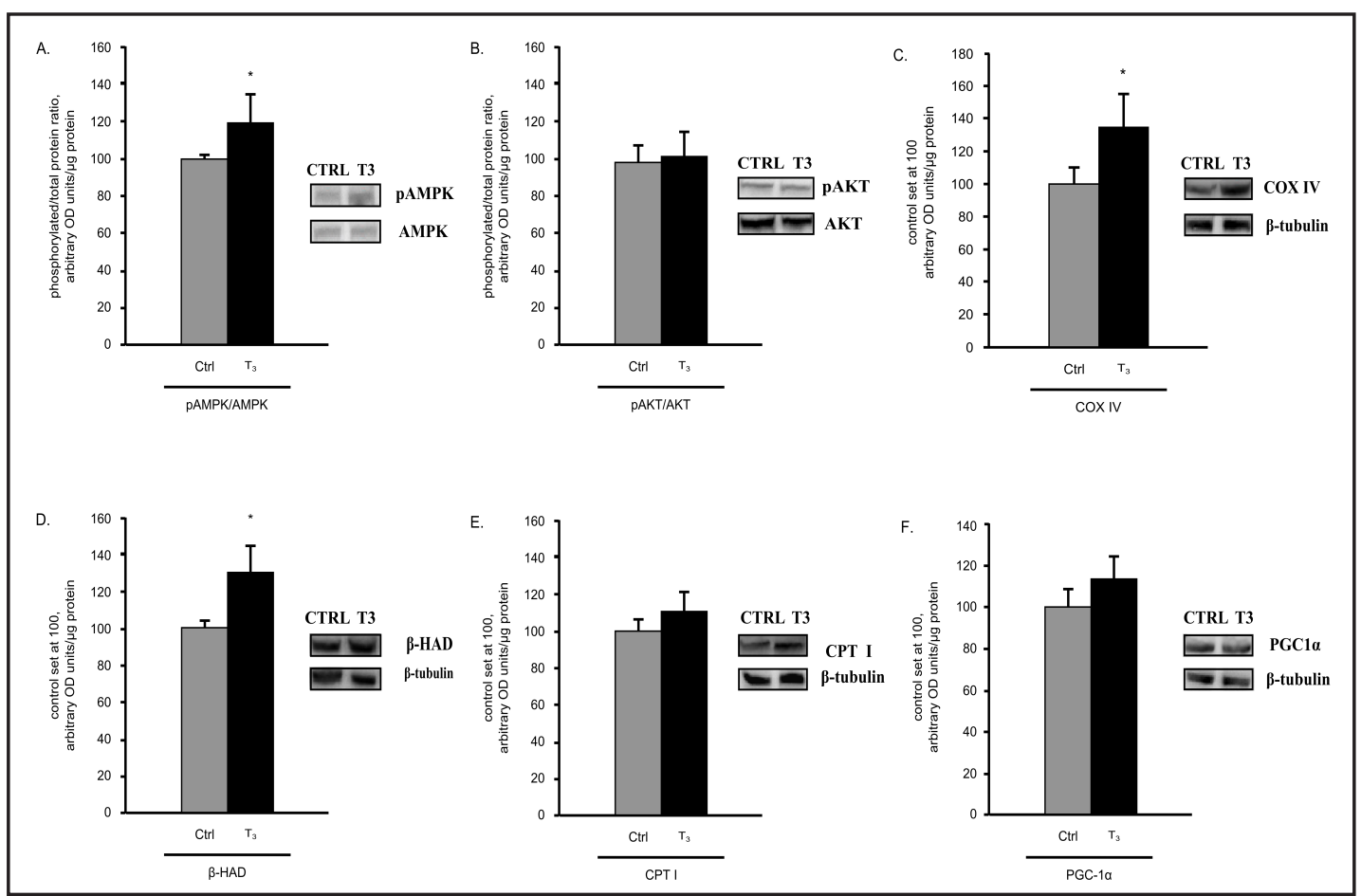

Fig. 4. Effect of hyperthyroidism on the expression of: (A) phosphorylated and total AMPK, (B) phosphorylated and total AKT, (C) COX IV protein (D) $\beta$-HAD protein, (E) CPT I protein and (F) PGC1 $\alpha$ protein in rat hearts. The animals were divided into two groups: control and treated with $\mathrm{T}_{3} . \mathrm{T}_{3}$ was injected subcutaneously with a dose of $50 \mu \mathrm{g} / 100 \mathrm{~g}$ of body weight, daily for 10 days, while control animals were treated with 0,9\% saline. Representative Western blots are shown. AMPK - AMP activated protein kinase, AKT - protein kinase B, COX IV - cytochrome c oxidase IV, $\beta$-HAD - $\beta$-hydroxyacyl-CoA dehydrogenase, CPT I - carnityne palmitoyltransferase I, PGC1 $\alpha$ - peroxisome proliferator-activated receptor- $\gamma$ coactivator- $1 \alpha$; $\mathrm{T}_{3}$ - triodothyronine. Data are shown as mean $\pm \mathrm{SD}\left(\mathrm{n}=8\right.$ in each group). ${ }^{*} \mathrm{P}<0.05$ statistically significant difference vs. $\mathrm{T}_{3}$ treatment.

responsible for observed changes in sphingolipid content. We noticed that the activity of neutral $\mathrm{Mg}^{2+}$-dependent SMase in muscle heart of hyperthyroid animals was reduced (Fig.3B, $-71 \%, \mathrm{P}<0.05)$ compared to control. In contrast, prolonged $\mathrm{T}_{3}$ treatment had no significant effect on acid SMase, although a trend towards an increase was noticed (Fig. 3B, $+17 \%, \mathrm{P}>$ 0.05 ). Subsequently, we observed that $\mathrm{T}_{3}$ treatment had only a minor effect on the activity of either neutral or alkaline ceramidase in heart muscle (Fig. 3A, P > 0.05).

\section{AMPK and AKT activation}

Subsequently, we investigated which cellular signaling pathways were activated by thyroid hormone treatment. We measured the ratio of phosphorylated to total form of both AMPK and AKT/PKB kinases in muscle hearts. In the hyperthyroidism, the level of AMPK ratio was markedly higher (Fig. 4A,+19\%, $\mathrm{P}<0.05$ ) compared to the baseline values. However, the AKT ratio was not different between control and hyperthyroid hearts (Fig. 4B, P >0.05).

The levels of mitochondrial protein - COX IV subunit, $\beta$-HAD or CPT I and regulator of mitochondrial biogenesis - PGC1 $\alpha$

We have also determined whether the hyperthyroidism evokes the changes in mitochondrial protein. We measured the COX IV, $\beta$-HAD, CPT I and PGC1 $\alpha$ levels in heart muscle. COX IV and $\beta$-HAD protein contents were significantly increased (Fig. 4C, D, $+40 \%$ and $+30 \%, \mathrm{P}<0.05$, respectively) in hyperthyroid hearts, and the level of CPT I protein as 
well as PGC1 $\alpha$ expression was slightly increased by T3 treatment (Fig. 4E, F, $+11 \%$ and $+13 \%$, $\mathrm{P}>0.05$, respectively).

\section{Discussion}

The current study examined the effects of hyperthyroidism on sphingolipid metabolism in rat heart muscle. We have demonstrated that prolonged, in vivo, $\mathrm{T}_{3}$ treatment increased the content of sphinganine, sphingosine, ceramide and sphingomyelin, but decreased the level of sphingosine-1-phosphate in cardiac myocytes. Accordingly, the changes in sphingolipids content were accompanied by decreased activity of neutral sphingomyelinase with no concomitant effects in ceramidases activities. This suggests, that although hyperthyroidism in the heart increases CER content, then it also tends to cause its conversion to sphingomyelin or sphingosine, which acts into opposite direction.

Previous studies showed that thyroid hormones can regulate cardiac metabolism via multiple cellular signaling pathways $[1,35]$. Here we purpose also to include the sphingomyelin pathway. In our study, CER accumulation in the heart of hyperthyroid rats is due to either acidic SMase activation or enhanced de novo sphingolipid synthesis. The main support for this hypothesis comes from studies in which plasma concentration of free fatty acids increases during hyperthyroidism [18,33] and as a consequence, their delivery to the heart also increases. This creates favorable conditions for increased ceramide synthesis, since it was shown that increased availability of extracellular palmitate was able to activate SPT-1, rate limiting enzyme for de novo synthesis of CER (Fig. 1) [13, 36, 37]. Furthermore, we observed that hyperthyroidism increased the activity of myocardial acid sphingomyelinase. This results, thereby, indicate that an enhancement in the content of CER was a consequence of increased formation of the compound from sphingomyelin. It seems that hyperthyroidism may increase activity of acidic SMase, which in turn elevates CER level, as has been reported for liver tissue homogenates, cultured hepatocytes [38] as well as in the adipose tissue of ob/ob mice [39] and high fat diet induced obesity in rodent models [40]. On the other hand, the present study also demonstrated that hyperthyroidism expressively increased sphingomyelin level. This would indicate that the rate of formation of sphingomyelin greatly exceeds the rate of its hydrolysis. Furthermore, an impact of neutral $\mathrm{Mg}^{2+}$ dependent SMase, an enzyme producing ceramide from sphingomyelin can be excluded, as hyperthyroidism was accompanied by a significant decrease in this enzyme activity. It may indicate that during hyperthyreosis the synthesis of sphingomyelin is exacerbated via the de novo production of CER which can subsequently be converted into sphingomyelin. On the other hand, the augmented level of SM with the lower rate of its degradation indicates that a concurrent increase in the activity of sphingomyelin synthase was prevailing. In accordance with those previous statements, diminished content of ceramide and lack of changes in the sphingomyelin concentration in hearts of hypothyroid rats, was also reported [23]. On the other hand, ceramide not only exerts multiple biological effects per se, but also serves as a precursor for a production of other bioactive sphingolipids, such as sphingosine and sphingosine-1-phosphate. Interestingly, despite of the close structural homology of ceramide, sphingosine and S1P, the biological role of these lipids is different and in most cases even opposite [41]. It was found that hyperthyroidism induces accumulation of sphingosine in rat heart muscle. However, under basal conditions the content of myocardial sphinganine is markedly low as compared to sphingosine, especially since sphinganine is considered to be a key intermediate substrate in the de novo CER synthesis pathway and sphingosine is one of the major CER degradation product [14]. Therefore, it is likely that under $\mathrm{T}_{3}$ stimulation sphinganine is phosphorylated preferentially over sphingosine which results in accumulation of the latter. It is important to note that the key destiny of sphingosine is phosphorylation with subsequent degradation [42]. Summing up it is likely that above mentioned effect(s) was a result of decreased rate of S1P formation from sphingosine. In line with this hypothesis, we observed a reduction of S1P content in heart muscle of rats 
subjected to hyperthyroidism. The low level of S1P in cells is tightly regulated in a special manner by the balance between synthesis and degradation, which is the case for many other signaling molecules. Because the breakdown of S1P is the only way for cellular lipids to exit the sphingolipid pathway, therefore S1P may be quickly released to the extracellular environment, where it bounds to the S1P2 receptor subtype [37, 43]. Additionally, it is likely that following $\mathrm{T}_{3}$ treatment, both intracellular S1P and SFO content rapidly exceeded CER levels suggesting rapid dephosphorylation of S1P to SFO. These data indicate that activation of ceramide catabolism may protect the heart against ceramide accumulation resulting from its augmented production de novo.

During hyperthyroidism, relatively high rates of glucose use can be maintained in muscle heart despite the concomitant, marked elevations in the circulating concentrations of free fatty acids, altering the supply of substrates available to the heart for energy metabolism $[1,6]$. It is widely accepted that increased plasma FFA availability which occurred during the hyperthyroidism leads to the accumulation of CER in tissues due to its augmented synthesis de novo. Studies in animal model of obesity and insulin resistant humans have demonstrated lipids accumulation in the heart and correlated these changes with potential mitochondrial dysfunction or apoptosis [44, 45]. Furthermore, fatty acid synthesis and oxidation in the heart are also regulated by thyroid hormones, which is initiated by binding of $\mathrm{T}_{3}$ to nuclear its receptor. Researchers have shown that experimental hyperthyroidism results in increased mitochondrial protein synthesis most frequently in heart, liver, and oxidative skeletal muscle, but skeletal muscle with lower oxidative capacity appear to be less responsive to hyperthyroidism $[8,35]$. The $\mathrm{T}_{3}$ treated rats used in the present study had significantly higher level of mitochondrial cytochrome c oxidase (COX IV) as well as $\beta$-hydroxyacyl-CoA dehydrogenase ( $\beta$-HAD), and trend to increase carnityne palmitoyltransferase I (CPT1). These proteins are involved in the regulation of muscle FA oxidation, but their relation to hyperthyroidism and sphingolipids accumulation are poorly understood. Although, a recent study, indicated that CPT I activity increases after $\mathrm{T}_{3}$ treatment (3-7 days) as the result of lowered concentration of malonyl-CoA, a potent inhibitor of CPT I [46, 47]. Furthermore, the PGC1 $\alpha$ transcriptional factor can also influence fatty acid oxidation rates via its overall regulation of mitochondrial biogenesis $[1,48]$. However, some studies have shown that hyperthyroidism did no significant increase in cardiac PGC1 $\alpha$ protein levels $[1,49]$. Also, in the present study we observed just a trend to increase in the PGC1 $\alpha$ content which was not statistically significant. Therefore, it is likely that $\mathrm{T}_{3}$ maintaining a constant PGC1 $\alpha$ level contribute to the control fatty acid oxidation in the hyperthyroid hearts.

Although most of the actions of thyroid hormones are mediated by changes in gene transcription, evidence has recently been provided indicating that triiodothyronine can activate AMP kinase acutely in heart via its membrane receptors $[8,10]$. This effect was associated with increased intracellular $\mathrm{Ca}^{2+}$ level, which subsequently increased contractility and enhanced energy demands. It is well established that AMPK acts as a fuel gauge for the cell, thus it is also an important regulator of myocardial energy metabolism by promoting glucose uptake and glycolysis as well as fatty acid oxidation [50]. Our research confirms that prolonged $\mathrm{T}_{3}$ treatment has the ability to alter the phosphorylation status of AMP kinase in myocardium, tissue with high-oxidative capacity. However Irrcher et al. reported that phosphorylation of AMPK after $2 \mathrm{~h} \mathrm{~T}_{3}$ treatment in heart was unaltered, while ERK 1/2 phosphorylation was decreased [8]. In our set prolonged $\mathrm{T}_{3}$ administration most likely resulted in activation of AMPK with subsequently increased intracellular $\mathrm{Ca}^{2+}$ level which further enhanced contractility and energy demands, provoking greater ATP utilization. This caused constant imbalance favoring AMPK activation, resulting in increased energy production as indicated by increased COX-IV and $\beta$-HAD mitochondrial proteins expression. On the other hand, it cannot be excluded that augmented FA demands together with enlarged FA availability, despite increased FA oxidation, might constantly contribute to intensification of de novo CER synthesis. To the best of our knowledge, there are no data in the literature addressing the influence of AMPK activation on the activity of enzymes involved in ceramide metabolism in heart muscle. 
Mikłosz et al.: Hyperthyroidism on Sphingolipids Metabolism in Heart

In summary, we found that prolonged $\mathrm{T}_{3}$ treatment increased sphingolipids metabolism which was reflected by higher concentration of SFA and CER in cardiac muscle. Furthermore, we speculate that hyperthyroidism-induced increase in heart SM concentration might be one of the mechanisms underlying maintenance of CER content at relatively low level due to its conversion to sphingomyelin together with decreased S1P.

\section{Acknowledgments}

This work was founded by the Leading National Research Center project no. 2/ KNOW/2013 and Medical University of Białystok (grants no. 143-18562L, 123-18803L).

A. Mikłosz and B. Łukaszuk are beneficiaries (scholarship-holders) of a project: „Studying, searching, commercializing - MUB doctoral support program” - UDAPOKL.08.02.01-20-069/11-00.

\section{Disclosure statement}

Authors declare no conflicts of interests.

\section{References}

1 Heather LC, Cole MA, Atherton HJ, Coumans WA, Evans RD, Tyler DJ, Glatz JFC, Luiken JJFP, Clarke K: Adenosine monophosphate- activated protein kinase activation, substrate transporter translocation, and metabolism in the contracting hyperthyroid rat heart. Endocrinology 2010;24:422-431.

- Messarah M, Saoudi M, Boumendjel A, Boulakoud MS, Feki AE: Oxidative stress induced by thyroid dysfunction in rat erythrocytes and heart. Environ Toxicol Pharmacol 2011;31:33-41.

3 Galli E, Pingitore A, Iervasi G: The role of thyroid hormone in the pathophysiology of heart failure: clinical evidence. Heart Fail Rev 2010;15:155-169.

4 Finck BN, Kelly DP: Peroxisome proliferator-activated receptor gamma coactivator-1 (PGC-1) regulatory cascade in cardiac physiology and disease. Circulation 2007;115: 2540-2548.

5 Finck BN: The PPAR regulatory system in cardiac physiology and disease. Cardiovasc Res 2007;73:269-277.

6 de Lange P, Senese R, Cioffi F, Moreno M, Lombardi A, Silvestri E, Goglia F, Lanni A: Rapid activation by 3,5,3'-L-triiodothyronine of adenosine 5'-monophosphate-activated protein kinase/acetyl-coenzyme A carboxylase and Akt/protein kinase B signaling pathways: relation to changes in fuel metabolism and myosin heavy-chain protein content in rat gastrocnemius muscle in vivo. Endocrinology 2008;149:64626470 .

7 Biondi B: Mechanisms in endocrinology: Heart failure and thyroid dysfunction. Eur J Endocrinol 2012;167:609-618.

-8 Irrcher I, Walkinshaw DR, Sheehan TE, Hood DA: Thyroid hormone (T3) rapidly activates p38 and AMPK in skeletal muscle in vivo. J Appl Physiol 2008;104:178-185.

-9 Park SH, Paulsen SR, Gammon SR, Mustard KJ, Hardie DG, Winder WW: Effects of thyroid state on AMPactivated protein kinase and acetyl-CoA carboxylase expression in muscle. J Appl Physiol 2002;93:20812088.

10 Yamauchi M, Kambe F, Cao X, Lu X, Kozaki Y, Oiso Y, Seo H: Thyroid hormone activates adenosine 5'-monophosphate-activated protein kinase via intracellular calcium mobilization and activation of calcium/calmodulin-dependent protein kinase kinase-beta. Mol Endocrinol 2008;22:893-903.

11 Krüger M, Sachse C, Zimmermann WH, Eschenhagen T, Klede S, Linke WA: Thyroid hormone regulates developmental titin isoform transitions via the phosphatidylinositol-3-kinase/ AKT pathway. Circ Res 2008;102:439-447.

12 Boslem E, Meikle PJ, Biden TJ: Roles of ceramide and sphingolipids in pancreatic $\beta$-cell function and dysfunction. Islets 2012;4:177-187. 
Mikłosz et al.: Hyperthyroidism on Sphingolipids Metabolism in Heart

13 Lipina C, Hundal HS: Sphingolipids: agents provocateurs in the pathogenesis of insulin resistance. Diabetologia 2011;54:1596-1607.

14 Baranowski M, Zabielski P, Blachnio A, Gorski J: Effect of exercise duration on ceramide metabolism in the rat heart. Acta Physiol (Oxf) 2008;192:519-529.

-15 Błachnio-Zabielska A, Baranowski M, Zabielski P, Górski J: Effect of exercise duration on the key pathways of ceramide metabolism in rat skeletal muscles. J Cell Biochem 2008;105:776-784.

16 Bikman BT, Summers SA: Ceramides as modulators of cellular and whole-body metabolism. J Clin Invest 2011;121:4222-4230.

-17 Ohanian J, Ohanian V: Sphingolipids in mammalian cell signalling. Cell Mol Life Sci 2001;58:2053-2068.

- 18 Chabowski A, Zendzian-Piotrowska M, Mikłosz A, Lukaszuk B, Kurek K, Górski J: Fiber specific changes in sphingolipid metabolism in skeletal muscles of hyperthyroid rats. Lipids 2013;48:697-704.

19 Podbielska M, Krotkiewski H, Hogan EL: Signaling and regulatory functions of bioactive sphingolipids as therapeutic targets in multiple sclerosis. Neurochem Res 2012;37:1154-1169.

20 Taniguchi M, Okazaki T: The role of sphingomyelin and sphingomyelin synthases in cell death, proliferation and migration-from cell and animal models to human disorders. Biochim Biophys Acta 2013;1841:692703.

21 Baranowski M, Charmas M, Długołęcka B, Górski J: Exercise increases plasma levels of sphingoid base-1 phosphates in humans. Acta Physiol (Oxf) 2011;203:373-380.

-22 Baranowski M, Blachnio-Zabielska A, Hirnle T, Harasiuk D, Matlak K, Knapp M, Zabielski P, Gorski J.: Myocardium of type 2 diabetic and obese patients is characterized by alterations in sphingolipid metabolic enzymes but not by accumulation of ceramide. J Lipid Res 2010: 51:74-80.

23 Górska M, Dobrzyń A, Langfort J, Górski J: Effect of hypothyreosis on the content of ceramides in rat tissues. J Physiol Pharmacol 2003;54:89-97.

-24 Hernandez OM, Discher DJ, Bishopric NH, Webster KA: Rapid activation of neutral sphingomyelinase by hypoxia-reoxygenation of cardiac myocytes. Circ Res 2000;86: 198-204.

25 Torrance CJ, Devente JE, Jones JP, Dohm GL: Effects of thyroid hormone on GLUT4 glucose transporter gene expression and NIDDM in rats. Endocrinology 1997;138: 1204-1214.

26 Izumi Y, Hidaka Y, Tada H, Takano T, Kashiwai T, Tatsumi KI, Ichihara K, Amino N: Simple and practical parameters for differentiation between destruction-induced thyrotoxicosis and Graves' thyrotoxicosis. Clin Endocrinol (Oxf) 2002; 57:51-58.

27 Folch J, Lees M, Sloane Stanley GH: A simple method for the isolation and purification of total lipides from animal tissues. J Biol Chem 1957;226:497-509.

-28 Van der Vusse GJ, Roemen THM, Reneman RS: Assessment of fatty acids in dog left ventricular myocardium. Biochim Biophys Acta 1980;617:347-352.

29 Min JK, Yoo HS, Lee EY, Lee WJ, Lee YM: Simultaneous quantitative analysis of sphingoid base 1-phosphates in biological samples by o-phthalaldehyde precolumn derivatization after dephosphorylation with alkaline phosphatase. Ann Biochem 2002;303:167-175.

-30 Bose R, Chen P, Loconti A, Grullich C, Abrams JM, Kolesnick RN: Ceramide generation by the Reaper protein is not blocked by the caspase inhibitor, p35. J Biol Chem 1998;273:28852-28859.

- 31 Liu B, Hannun YA: Sphingomyelinase assay using radiolabeled substrate. Methods Enzymol 2000;311:164167.

-32 Nikolova-Karakashian M, Merrill AH Jr: Ceramidases. Methods Enzym 2000;311:194-201.

-33 Miklosz A, Chabowski A, Zendzian-Piotrowska M, Gorski J: Effects of hyperthyroidism on lipid content and composition in oxidative and glycolytic muscles in rats. J Physiol Pharmacol 2012;63:403-410.

-34 Kudelska G, Górski J, Świątecka J, Górska M: Effect of exercise on glycogen metabolism in muscles of triiodothyronine-treated rats. Eur J Appl Physlol 1996;72:496-501.

-35 Short KR, Nygren J, Sreeekumaran Nair K: Effect of T3-induced hyperthyroidism on mitochondrial and cytoplasmic protein synthesis rates in oxidative and glycolytic tissues in rats. Am J Physiol Endocrinol Metab 2007;292:E642-E647.

-36 Mikłosz A, Łukaszuk B, Baranowski M, Górski J, Chabowski A: Effects of inhibition of serine palmitoyltransferase (SPT) and sphingosine kinase 1 (SphK1) on palmitate induced insulin resistance in L6 myotubes. PLoS One 2013;8:e85547. 


\section{Cellular Physiology $\quad$ Cell Physiol Biochem 2015;35:755-766 and Biochemistry \\ Mikłosz et al.: Hyperthyroidism on Sphingolipids Metabolism in Heart}

-37 Hu W, Bielawski J, Samad F, Merrill AH Jr, Cowart LA: Palmitate increases sphingosine-1-phosphate in C2C12 myotubes via upregulation of sphingosine kinase message and activity. J Lipid Res 2009;9:18521862.

38 Babenko NA: Long- and short-term effects of thyroxine on sphingolipid metabolism in rat liver. Med Sci Monit 2005;11:BR131-138.

-39 Boini KM, Zhang C, Xia M, Poklis JL, Li PL: Role of sphingolipid mediator ceramide in obesity and renal injury in mice fed a high-fat diet. J Pharmacol Exp Ther 2010;334: 839-846.

$\checkmark 40$ Chocian G, Chabowski A, Zendzian-Piotrowska M, Harasim E, Łukaszuk B, Górski J: High fat diet induces ceramide and sphingomyelin formation in rat's liver nuclei. Mol Cell Biochem 2010;340:125-131.

-41 Alewijnse AE, Peters SL: Sphingolipid signalling in the cardiovascular system: good, bad or both? Eur J Pharmacol 2008;585:292-302.

42 Le Stunff H, Milstien S, Spiegel S: Generation and metabolism of bioactive sphingosine-1-phosphate. J Cell Biochem 2004; 92: 882-899.

43 Johnson KR, Becker KP, Facchinetti MM, Hannun YA, Obeid LM: PKC-dependent activation of sphingosine kinase 1 and translocation to the plasma membrane. Extracellular release of sphingosine-1-phosphate induced by phorbol 12-myristate 13-acetate (PMA). J Biol Chem 2002;277:35257-35262.

44 Zhou YT, Grayburn P, Karim A, Shimabukuro M, Higa M, Baetens D, Orci L, Unger RH: Lipotoxic heart disease in obese rats: implications for human obesity. Proc Natl Acad Sci USA 2000;97:1784-1789.

45 Chiu HC, Kovacs A, Ford DA, Hsu FF, Garcia R, Herrero P, Saffitz JE, Schaffer JE: A novel mouse model of lipotoxic cardiomyopathy. J Clin Invest 2001;107:813-822.

46 Bruce CR, Brolin C, Turner N, Cleasby ME, van der Leij FR, Cooney GJ, Kraegen EW: Overexpression of carnitine palmitoyltransferase I in skeletal muscle in vivo increases fatty acid oxidation and reduces triacylglycerol esterification. Am J Physiol Endocrinol Metab 2007;292:E1231-E1237.

-47 Sugden MC, Priestman DA, Orfali KA, Holness MJ: Hyperthyroidism facilitates cardiac fatty acid oxidation through altered regulation of cardiac carnitine palmitoyltransferase: studies in vivo and with cardiac myocytes. Horm Metab Res 1999;31:300-306.

48 Branvold DJ, Allred DR, Beckstead DJ, Kim HJ, Fillmore N, Condon BM, Brown JD, Sudweeks SN, Thomson DM, Winder WW: Thyroid hormone effects on LKB1, M025, phospho-AMPK, phosphor-CREB, and PGC-1 $\alpha$ in rat muscle. J Appl Physiol 2008;105:1218-1227.

-49 Irrcher I, Adhihetty PJ, Sheehan T, Joseph AM, Hood DA: PPAR $\gamma$ coactivator- $1 \alpha$ expression during thyroid hormone- and contractile activity-induced mitochondrial adaptations. Am J Physiol Cell Physiol 2003;284:C1669-C1677.

50 Tavares FM, da Silva IB, Gomes DA, Barreto-Chaves ML: Angiotensin II type 2 receptor (AT2R) is associated with increased tolerance of the hyperthyroid heart to ischemia-reperfusion. Cardiovasc Drugs Ther 2013;27:393-402. 